\title{
Investing in a healthy lifestyle strategy: is it worth it?
}

\author{
Tarik Benmarhnia $(1) \cdot$ Pierre-Alexandre Dionne $\cdot$ Éric Tchouaket $\cdot$ \\ Alvine K. Fansi · Astrid Brousselle
}

Received: 25 September 2015/Revised: 15 August 2016/Accepted: 16 August 2016/Published online: 1 September 2016

(c) The Author(s) 2016. This article is published with open access at Springerlink.com

\begin{abstract}
Objectives In Quebec, various actors fund activities aimed at increasing physical activity, improving eating habits and reducing smoking. The objective was to evaluate how effective does the healthy lifestyle habits promotion (HLHP) strategy need to be to make to offset its costs. Methods First, we built the logic model of the HLHP strategy. We then assessed the strategy's total cost as well as the direct health care expenditures associated with lifestyle-related risk factors (smoking, physical inactivity,
\end{abstract}

T. Benmarhnia and P.-A. Dionne equally contributed to this work.

Electronic supplementary material The online version of this article (doi:10.1007/s00038-016-0884-y) contains supplementary material, which is available to authorized users.

T. Benmarhnia ( $\square)$

Institute for Health and Social Policy, McGill University, Meredith, Charles House, 1130 Pine Avenue West Montreal, Montreal, QC H3A 1A3, Canada

e-mail: tarik.benmarhnia@mcgill.ca

P.-A. Dionne · A. Brousselle

Centre de recherche de l'hôpital Charles-LeMoyne, Community health sciences department, Université de Sherbrooke,

Longueuil, QC, Canada

e-mail: pierre-alexandre.Dionne@usherbrooke.ca

A. Brousselle

e-mail: astrid.brousselle@usherbrooke.ca

É. Tchouaket

Department de Sciences Infirmières, Universté du Québec en

Outaouais, Gatineau, QC, Canada

e-mail: Eric.Tchouaket@uqo.ca

A. K. Fansi

Institut national d'excellence en santé et en services sociaux

(INESSS), Quebec, Canada

e-mail: afansi@yahoo.com insufficient intake of fruits and vegetables, obesity and overweight). Finally, we estimated the break-even point beyond which the economic benefits of the HLHP strategy would outweigh its costs.

Results The HLHP strategy cost for 2010-2011 was estimated at $\$ 110$ million. Direct healthcare expenditures associated with lifestyle-related risk factors were estimated at $\$ 4.161$ billion. We estimated that $47 \%$ of these expenditures were attributable to these risk factors.

Conclusions We concluded that the HLHP strategy cost corresponded to $5.6 \%$ of the annual healthcare expenditures attributable to these risk factors. This study compared the economic value of HLHP activities against healthcare expenditures associated with targeted risk factors.

Keywords Economic evaluation - Public health ·

Health policy - Burden of disease - Attributable fraction -

Return on investment - Risk factors - Economic benefits .

Healthy lifestyle habits promotion

\section{Introduction}

Both the epidemiological landscape and public health threats have evolved considerably over the past decade in Western countries, moving from risks of infectious disease epidemics to a strong prevalence of lifestyle-related health problems (Brownson et al. 2006). In the United States, for example, health problems related to lifestyle habits (smoking, sedentary lifestyle, poor nutrition, excessive alcohol consumption) account for 900,000 deaths annually, or nearly $40 \%$ of total mortality (Abraham et al. 2009; Cohen et al. 2008). Effective public health programs can increase life expectancy, improve quality of life and reduce health system costs (Goldsmith et al. 2004). Yet despite the 
available evidence and the recognized health and economic burdens associated with cardiovascular and respiratory diseases, diabetes and cancer, public health programs represent only a very meagre portion of total health spending (Brownson et al. 2006). Neumann et al. (2008) point out that even if the value of public health programs appears obvious in the light of scientific knowledge, the chronic underfunding of public health activities indicates that public is not very aware of their value.

In Quebec, various actors fund activities related to environmental action and education that are aimed at increasing physical activity, improving eating habits and reducing smoking (Ministère de la Santé et des Services sociaux (MSSS) 2008). The objective of our study was to evaluate the economic value of such activities in Quebec which, for purposes of this study, we refer to collectively as the healthy lifestyle habits promotion (HLHP) strategy. As the effectiveness of this large scope policy has not been evaluated, we evaluated how effective does the HLHP strategy need to be to make to offset its costs. More specifically, we compared investments to economic benefits, analysing at what point HLHP costs were outweighed by economic benefits, measured as savings in healthcare expenditures related to a reduction in risk factors targeted by HLHP activities. We specifically define the economic benefits of the HLHP strategy as economic savings in direct healthcare expenditure (i.e. drugs, hospital care, and medical care).

In this article, we first describe our methodology, after which we present the results and discuss the innovative nature and limitations of this approach. This article may be of interest to public health authorities and researchers, both for the information it provides on the economic value of HLHP activities in Quebec as compared to healthcare expenditures associated with targeted risk factors, and for the methodology used to capture information that encompasses a broad range of activities and programs, in a context where actual effectiveness is not known.

\section{Methods}

The methodology (Fig. 1) for this study consisted of: (1) building the logic model for the HLHP strategy and related activities (Brousselle and Champagne 2011); (2) assessing the total cost for the HLHP strategy; (3) assessing direct healthcare expenditures associated with lifestyle-related risk factors (smoking, physical inactivity, insufficient intake of fruits and vegetables, obesity and overweight); and (4) estimating the point at which savings in healthcare expenditures related to unhealthy lifestyle habits outweigh HLHP strategy costs (break-even point). In cases of uncertainty, to obtain a valid and conservative estimate we overestimated HLHP strategy costs and underestimated expenditures attributable to complications related to risk factors.

Our approach has similarities with economic evaluation and program evaluation methods: logic model (Brousselle and Champagne 2011), cost-benefit (Commonwealth Department of Health and Ageing 2003; Drummond et al. 2005), cost-offset type studies (Chiles et al. 1999; Kelly et al. 2005), and cost-consequence analysis (Canadian Agency for Drugs and Technologies in Health (CADTH) 2006; Coast 2004). The methods used in this economic evaluation are, to some extent, similar to those used in the previous studies assessing the economic impact of chronic diseases in other Canadian provinces or other countries (Conference Board of Canada 2010; Katzmarzyk and Janssen 2004; Krueger et al. 2013; Scarborough et al. 2011), and the economic benefits of a water fluoridation program (Tchouaket et al. 2013).

\section{HLHP strategy logic model development}

The logic model provides an exhaustive representation of the resources, activities (programs, interventions), expected effects, and impacts associated with those effects (Drummond et al. 2005; Funnell and Rogers 2011). To build this logic model, we consulted the grey and the scientific literatures. The model underwent two rounds of validation by public health experts and people closely involved in the strategy's design and coordination.

\section{Assessing the total cost of Quebec's HLHP strategy}

The strategy we evaluated is made up of many programs and activities funded by various actors at the federal, provincial, regional, and community levels. As such, to identify all the activities aimed at promoting healthy lifestyle habits and quantify how much is allocated to each activity would present a very complex challenge. We were able to get around this problem by identifying primary sources of funding and evaluating the total amounts granted by each of them annually.

To identify the primary funders and the amounts invested, we consulted the grey literature (financial reports of organizations, government reports) and people involved in public health administration. A top down costing approach was selected to estimate the cost of the HLHP strategy. We used the standardized costs of the Programme national de santé publique-PNSP (Quebec Public Health Program), which are primary estimates of the human resources needed at local and regional levels to plan, implement, and coordinate public health activities (Direction générale de la santé publique-DGSP 2010). These data are estimates that are likely higher than what is actually 
Fig. 1 Methodological process. Canada 2016

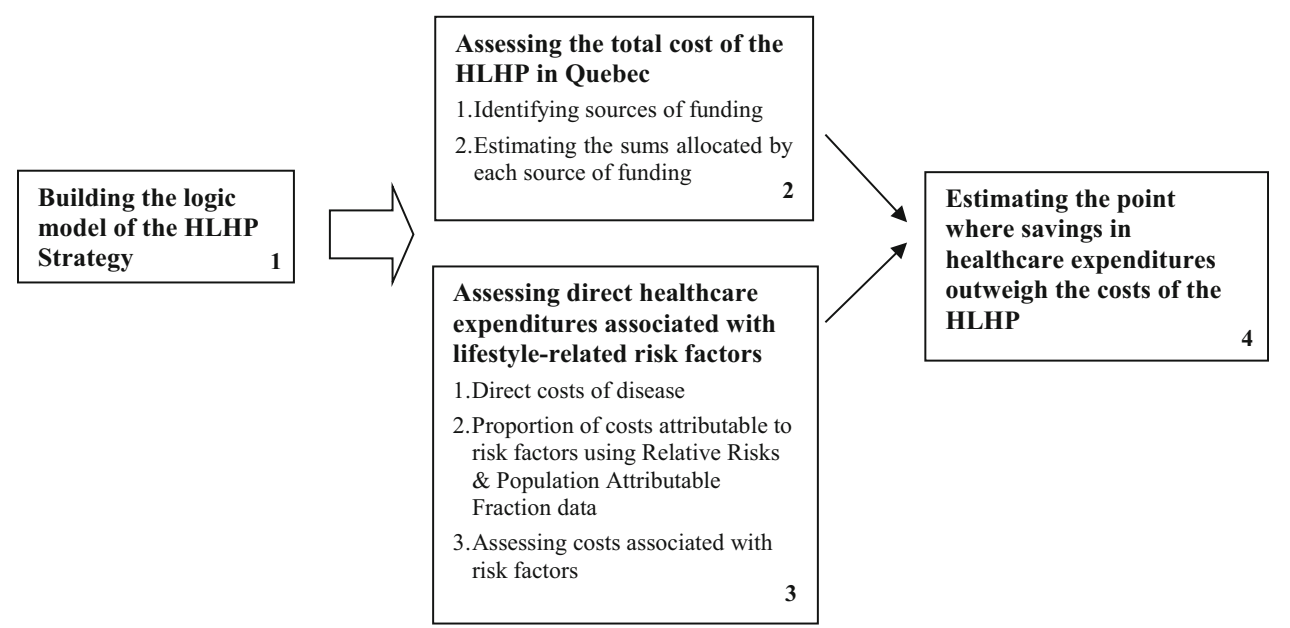

invested in public health in Quebec, making them conservative estimates for determining the break-even point. We used 2010-2011 fiscal year costs for the analyses. The data on the costs of prevention activities were validated by experts working for Quebec's Ministry of Health and Social Services (MSSS).

Assessing direct healthcare expenditures associated with lifestyle-related risk factors

\section{Cost of diseases associated with unhealthy habits in Quebec}

The first step in assessing healthcare expenditures attributable to modifiable risk factors is to calculate the costs of chronic diseases associated with those factors. As illustrated in the logic model, the diagnoses retained for calculating disease costs were those shown in the literature to be associated with the risk factors targeted by the HLHP strategy (smoking, insufficient intake of fruits and vegetables, physical inactivity, obesity and overweight). We did not include in our calculations all the healthcare expenditures attributable to these risk factors, but rather the principal ones, such that the calculated level of effectiveness at which economic benefits surpass HLHP strategy costs is a conservative estimate (higher than what it would be in reality). It should be noted that, in our study, we excluded from the calculation of costs attributable to risk factors: (1) indirect costs (e.g. mortality, lost productivity); (2) costs related to other illnesses associated with the risk factors (e.g. vascular disease related to diabetes, some types of cancers); and (3) other nonmedical outcomes such as improved quality of life and higher self-esteem. Hence, by not quantifying the indirect costs, we considerably underestimated the costs attributable to risk factors.

Using data from the Economic Burden of Illness in Canada (EBIC) studies (Public Health Agency of Canada
(PHAC) 2000), we calculated the direct costs of these chronic diseases in Quebec in 2010 for hospitalizations, ambulatory care visits, and medications. This is the same source of data on illness costs that has been used in other studies to determine the costs of some chronic diseases in Canada (Conference Board of Canada 2010; Krueger et al. 2013; Katzmarzyk and Janssen 2004). The data in the EBIC report on the costs of illnesses are the result of complex analyses performed over more than 10 years by the Public Health Agency of Canada (PHAC) on data from several Canadian Institute for Health Information (CIHI) databanks and from self-reported surveys, including the Canadian Community Health Survey (CCHS) (Health Canada 2002). To calculate the costs of illness in 2010, we extrapolated the cost data from 2000 over an 11-year span using CIHI's National Health Expenditure Database (CIHI 2012). In this way, we obtained a projection of the annual costs of illness in relation to changes in spending in different sectors of health-related activity (e.g. medications, hospitalizations, medical visits).

Assessing the proportion of the costs attributable to the risk factors

Using cost data attributable to specific effects (medications, hospitalizations, medical visits), we calculated the number of cases of illness attributable to the risk factors under consideration (smoking, insufficient intake of fruits and vegetables, physical inactivity). For this, we calculated the proportions attributable to each risk factor for all the illnesses.

Many epidemiologic studies have assessed the link between lifestyle habits or changes (such as smoking cessation) and chronic disease incidence. In this study, we considered various exposures and health effects. Based on the relationships expressed between a given exposure and a corresponding effect-for example, with relative risks (RR) - and using the prevalence of this exposure, it is 
possible to calculate a population attributable fraction (PAF) using the formula 1.

$\mathrm{PAF}=P e(\mathrm{RR}-1) / P e(\mathrm{RR}-1)+1$

where $P e$ represents the exposure prevalence (in a given context) and RR the relative risk, expressing the relationship between exposure and effect.

PAFs were calculated separately for each exposure/ health effect relationship (RR) considered in this study. From each PAF it was then possible to calculate a number of cases attributable to one exposure or, in this situation, the proportion of disease costs attributable to the risk factor. We calculated adjusted PAFs following the approach described in studies by Benichou (2001), Hanley (2001), and Steenland and Armstrong (2006) to consider the level of exposure for a given risk factor (e.g. smokers, occasional smokers, former smokers, and never smokers) and multiexposure for one given health effect (e.g. the combined impact of smoking and physical inactivity and obesity). PAF estimates were adjusted for level of exposure when data was available (e.g. smoker, occasional smoker, former smoker, never smoker). By doing this dual adjustment, we avoided double-counting the economic burden of the risk factors (Krueger et al. 2013). To calculate the number of cases (for the health effects considered) and the proportion of costs attributable to each exposure, we undertook a multi-stage process of systematic review and data analysis, details of which are presented in the supplemental material.

Evaluating the point at which savings in healthcare expenditures outweigh the costs of the HLHP strategy

We then estimated the point at which savings in healthcare expenditures related to unhealthy lifestyle habits outweighed HLHP strategy costs. To estimate this break-even point $(\%)$, we used formula 2 :

Total amount allocated to HLHP strategy $(\$)$ $\overline{\text { Direct health expenditures attributable to targeted risk factors }(\$)}$

The break-even threshold represents the minimal level of savings required to offset the cost of the HLHP strategy; in fact, the real threshold is most certainly below the calculated threshold, since we did not include in our calculations all the costs attributable to risk factors.

\section{Discounting}

To take into account the fact that effects occur several years after investments in prevention activities, we modelled the occurrence of effects on different time horizons (0, 5, 10, 15 and 20 years) by discounting the costs attributable to the risk factors using discount rates recommended by the Center for
Public Health Excellence at National Institute for Health and Clinical Excellence (NICE 2011) (1.5\% for health benefits and $3.5 \%$ for costs) and using Canadian Institute for Health Information (Canadian Institute for Health Information (CIHI) 2012) data on health expenditures in Canada to project the increases in healthcare expenditures attributable to these illnesses. Between 2000 and 2010, health expenditures (in 1997 constant dollars) increased by $4.4 \%$ annually. We assumed costs attributable to the risk factors would increase at the same rate $(4.4 \%)$ as health expenditures in Canada over recent years. Different sensitivity analyses were conducted that are presented in the supplemental material.

\section{Results}

The logic model

Given the scope and complexity of the HLHP strategy, the logic model was divided into two different models: one presenting the resources, activities, and key effects (Fig. 2); and another depicting the chain of effects of adopting healthy lifestyle habits (Figure S1). It is important to recall that these models were built with the idea that only health expenditures avoided due to reduction in chronic illnesses (direct costs of risk factors) would be estimated for the economic analysis.

\section{Cost of the HLHP strategy}

Healthy lifestyle habits promotion and chronic disease prevention activities were grouped into five categories based on type of funding. For each category, Table S2 presents all the subcategories of activities, their funding sources, examples of interventions, and their costs for the year 2010-2011.

Total cost was estimated at approximately $\$ 110$ million for the 2010-2011 fiscal year (amounts given in this paper are in Canadian dollars). As presented in Table S2, some costs could not be quantified for some sources of funding. These costs seem to be negligible compared to the main sources of funding. Furthermore, certain costs may be overestimated; in particular the PNSP's standardized costs. For the sensitivity analyses, we assumed the costs of the HLHP strategy could vary between $\$ 90$ million and $\$ 150$ million.

Direct healthcare expenditures associated with lifestylerelated risk factors

Cost of diseases associated with unhealthy habits in Quebec

The total direct healthcare expenditures of chronic diseases selected for our study in Quebec in 2010 are presented in 


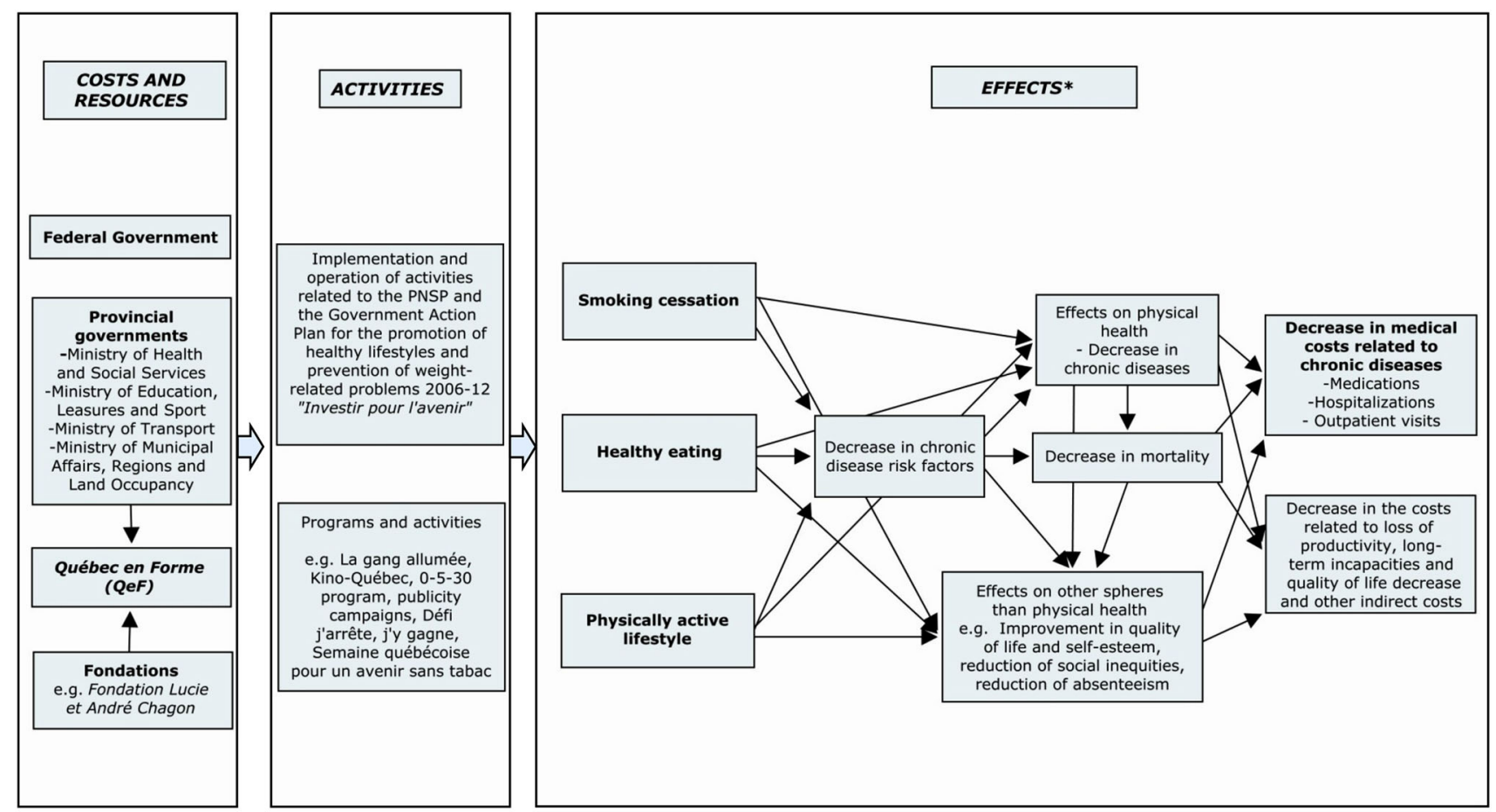

* The effects of adopting and maintaining healthy lifestyles are presented in further detail in Figure S1.

Fig. 2 Logic model of the healthy lifestyle habits promotion strategy in Quebec. Canada 2016

Table 1 Economic burden of illness by diagnostic category in Quebec

\begin{tabular}{|c|c|c|c|c|c|}
\hline \multirow[t]{2}{*}{ Code } & \multirow[t]{2}{*}{ Cause } & \multicolumn{4}{|l|}{ Direct costs ${ }^{*}{ }^{\dagger}$} \\
\hline & & Drugs & Hospital care & Medical care & All direct costs \\
\hline W000 & All causes & $\$ 6,267,268,479$ & $\$ 10,801,577,118$ & $\$ 4,647,884,743$ & $\$ 21,716,730,340$ \\
\hline W060 & A. Malignant tumours & & & & \\
\hline W064 & 4. Colon and rectal cancer & $\$ 3,682,912$ & $\$ 112,028,852$ & $\$ 16,223,691$ & $\$ 131,935,455$ \\
\hline W067 & 7. Tracheal, bronchial and lung cancer & $\$ 4,750,870$ & $\$ 123,715,726$ & $\$ 23,135,123$ & $\$ 151,601,720$ \\
\hline W069 & 9. Breast cancer & $\$ 13,768,738$ & $\$ 42,144,588$ & $\$ 21,509,603$ & $\$ 77,422,929$ \\
\hline W079 & C. Type 2 diabetes & $\$ 147,840,004$ & $\$ 132,547,663$ & $\$ 99,296,278$ & $\$ 379,683,944$ \\
\hline W104 & G. Cardiovascular diseases & & & & \\
\hline W106 & 2. Hypertensive disease & $\$ 741,822,143$ & $\$ 57,843,016$ & $\$ 169,159,096$ & $\$ 968,824,255$ \\
\hline W107 & 3. Ischemic heart disease & $\$ 290,308,382$ & $\$ 505,568,277$ & $\$ 167,814,583$ & $\$ 963,691,242$ \\
\hline W108 & 4. Cerebrovascular disease & $\$ 22,588,070$ & $\$ 396,509,597$ & $\$ 38,292,634$ & $\$ 457,390,301$ \\
\hline W111 & H. Respiratory conditions & & & & \\
\hline W112 & 1. Chronic obstructive pulmonary disease & $\$ 83,672,505$ & $\$ 229,684,077$ & $\$ 81,379,783$ & $\$ 394,736,365$ \\
\hline W113 & 2. Asthma & $\$ 206,389,146$ & $\$ 69,830,400$ & $\$ 59,673,740$ & $\$ 335,893,285$ \\
\hline W125 & L. Musculoskeletal diseases & & & & \\
\hline W127 & 2. Osteoarthritis (arthrosis) & $\$ 57,525,894$ & $\$ 138,020,356$ & $\$ 43,047,497$ & $\$ 238,593,747$ \\
\hline
\end{tabular}

Canada 2016

* Forecasts based on health expenditure data from Canadian Institute for Health Information (CIHI) and Economic Burden of Illness in Canada (EBIC) data from the Public Health Agency of Canada (Katzmarzyk and Janssen 2004; Kelly et al. 2005; Krueger et al. 2013).

$\dagger$ The chronic diseases selected in our economic model (subcategories A4, A7, A9, C, G2, G3, G4, H1, H2, L2) were responsible for $\$ 4.161$ billion of direct healthcare spending in 2010

Table 1. Using the health expenditure data from CIHI and data from the EBIC survey, we estimated the total all-cause direct healthcare expenditures to be $\$ 21.72$ billion in 2010 in Quebec-and more specifically, as related to the diseases targeted in our study, $\$ 379$ million for diabetes mellitus, $\$ 3.45$ billion for cardiovascular diseases, over 
$\$ 700$ million for asthma and chronic obstructive pulmonary diseases (COPD), and over $\$ 360$ million for lung, colorectal, and breast cancers. Based on our forecasts, the chronic diseases selected in our economic model (subcategories presented in Table 1) were responsible for $\$ 4.161$ billion of direct healthcare spending in 2010. Therefore, chronic diseases related to modifiable risk factors were responsible for an important part (approximately one fifth) of total direct healthcare expenditures in 2010 in Quebec.

Assessing the proportion of the costs attributable to the risk factors

The studies included in our literature review and the selected RRs for each risk factor are presented in Table S1. Relative risks, the prevalence of exposure, and the PAFs of total chronic disease costs for each risk factor and each chronic disease are presented in Table 2. According to the CCHS survey, the prevalence of smoking among persons aged 12 years and older in Quebec was $18.9 \%$ among males and $15.7 \%$ among females in 2009-2010. In that same year, $56.7 \%$ of men and $39.7 \%$ of women had insufficient intake of fruits and vegetables (fewer than five portions daily), and $58.2 \%$ of men and $63.5 \%$ of women did not reach the recommended level of physical activity. The prevalence of obesity and overweight were 17.5 and $41.0 \%$, respectively, in men and 15.4 and $27.1 \%$ in women (Table 2).

Table 2 presents PAF estimates adjusted for multiple exposures to each disease (combined effect of having multiple risk factors for the same disease); the crude estimates of costs associated with each risk factor, and the adjusted costs associated with these risk factors for specific diseases assessed using the adjusted PAF estimates (Table 3). The targeted risk factors were responsible for over $\$ 1$ billion of cardiovascular disease costs (respectively, \$522, \$436, and \$161 million for ischemic heart diseases, hypertension, and stroke) in Quebec in 2010. In addition, they were also responsible for most of the direct healthcare expenditures for COPD (\$222 million), lung cancer (\$111 million), and diabetes mellitus (\$259 million). Looking specifically at each risk factor, smoking, obesity and overweight, insufficient intake of fruits and vegetables, and physical inactivity were responsible for \$699 million, \$951 million, \$403 million, and \$232 million in direct healthcare expenditures, respectively, in 2012.

After adjusting for multiple exposures, the sum of all direct healthcare expenditures attributable to the selected risk factors was estimated at $\$ 1.958$ billion in 2010 , corresponding to nearly half the total expenditures for related chronic diseases ( $\$ 4.16$ billion). In fact, these risk factors were responsible for $47 \%$ of all direct healthcare expenditures associated with the chronic diseases included in our study.

The point at which healthcare expenditure savings outweigh HLHP strategy costs

Using the baseline estimate of the costs of the HLHP strategy (\$110 million), we estimated that the costs of HLHP activities in Quebec represented $5.62 \%$ of the total healthcare expenditures attributable to the risk factors ( $\$ 1.958$ billion). This estimate does not include these diseases' indirect costs, such as the economic impact of mortality and lost productivity due to long-term and short-term disabilities, nor the direct costs of other diseases associated with unhealthy lifestyle choices. Hence, the real break-even point is likely to be lower than the estimate we calculated.

\section{Discounting the effects}

Table S3 presents the results of the analyses of the impact of discounting the effects (3.5\% discount rate) and accounting for increases in healthcare spending over different time horizons. If the economic benefits (savings from disease avoidance) are assumed to occur 10, 15, or 20 years after the HLHP activities, the break-even point decreases to $5.15,4.93$, and $4.72 \%$, respectively.

\section{Discussion}

Quebec's HLHP strategy is a large-scale program encompassing all activities related to environmental actions and education that are aimed at increasing physical activity, improving eating habits, and reducing tobacco use (Ministère de la Santé et des Services sociaux (MSSS 2008). The costs of these activities were estimated at $\$ 110$ million in 2010. Very few studies have comprehensively estimated the total cost of health promotion activities. One other study that attempted to quantify the costs of such activities in Quebec produced a higher estimate of $\$ 127$ million in 2008 (\$31 million for smoking cessation programs and $\$ 96.3$ million for obesity prevention activities) (Manuel et al. 2009). In addition, the objective of this paper was to assess how effective does Quebec's HLHP strategy need to be to make to offset its costs. This analysis goes beyond a separated calculation of the two sides of the costs. By estimating the point at which healthcare expenditure savings outweigh HLHP strategy costs (5.62\%), we were thus able to highlight the potential amplitude of further public health investments.

In this study, healthcare expenditures attributable to the risk factors targeted by the HLHP strategy were estimated 
Table 2 Assessment of Population attributable fractions (PAF) of total direct healthcare costs

\begin{tabular}{|c|c|c|c|c|c|c|c|c|c|c|c|}
\hline \multirow[t]{2}{*}{ Chronic diseases } & \multirow[t]{2}{*}{ Risk factors (RF) } & \multicolumn{5}{|l|}{ Men } & \multicolumn{5}{|c|}{ Women } \\
\hline & & $\mathrm{RR}^{\mathrm{a}}$ & \multicolumn{2}{|c|}{$\left(95 \% \mathrm{CI}^{\mathrm{b}}\right)$} & $P^{\mathrm{c}}(\%)$ & $\begin{array}{l}\text { Adj. } \\
\text { PAF }^{\mathrm{d}}(\%)\end{array}$ & $\mathrm{RR}^{\mathrm{a}}$ & \multicolumn{2}{|c|}{$\left(95 \% \mathrm{CI}^{\mathrm{b}}\right)$} & $P^{\mathrm{c}}(\%)$ & $\begin{array}{l}\text { Adj. } \\
\text { PAF }^{\text {d }}(\%)\end{array}$ \\
\hline \multicolumn{12}{|l|}{ (1) Pulmonary diseases } \\
\hline \multirow{4}{*}{$\begin{array}{l}\text { Chronic obstructive } \\
\text { pulmonary disease }\end{array}$} & Smoker & 4.11 & 3.28 & 5.15 & 18.9 & 59.9 & 3.28 & 2.35 & 4.58 & 15.7 & 39.4 \\
\hline & Occasional smoker & 2.14 & 1.87 & 2.46 & 6.3 & & 2.14 & 1.87 & 2.46 & 4.9 & \\
\hline & Former smoker & 2.97 & 2.63 & 3.34 & 42.3 & & 1.61 & 1.46 & 1.77 & 38.8 & \\
\hline & $\begin{array}{l}\text { Insufficient consumption of } \\
\text { fruits and vegetables }\end{array}$ & 1.32 & 1.09 & 1.67 & 56.7 & 15.2 & 1.32 & 1.09 & 1.67 & 39.7 & 11.1 \\
\hline \multirow[t]{4}{*}{ Asthma } & Smoker & 1.70 & 1.30 & 2.20 & 18.9 & 13.6 & 1.30 & 0.80 & 2.30 & 15.7 & 6.3 \\
\hline & Occasional smoker & 1.40 & 1.20 & 1.60 & 6.3 & & 1.40 & 1.20 & 1.60 & 4.9 & \\
\hline & Obesity & 1.43 & 1.14 & 1.79 & 17.5 & 13.6 & 1.78 & 1.36 & 2.32 & 15.4 & 15.8 \\
\hline & Overweight & 1.20 & 1.08 & 1.33 & 41.0 & & 1.25 & 1.05 & 1.49 & 27.1 & \\
\hline \multicolumn{12}{|l|}{ (2) Cancers } \\
\hline \multirow[t]{3}{*}{ Lung cancer } & Smoker & 8.96 & 6.63 & 12.1 & 18.9 & 73.0 & 7.58 & 5.36 & 10.7 & 15.7 & 68.1 \\
\hline & Former smoker & 3.85 & 2.77 & 5.34 & 42.3 & & 3.85 & 2.77 & 5.34 & 38.8 & \\
\hline & $\begin{array}{l}\text { Insufficient consumption of } \\
\text { fruits and vegetables }\end{array}$ & 1.21 & 1.04 & 1.45 & 56.7 & 10.6 & 1.21 & 1.04 & 1.45 & 39.7 & 7.7 \\
\hline \multirow[t]{2}{*}{ Breast cancer } & Physical inactivity & & & & & & 1.49 & 1.00 & 2.27 & 63.5 & 23.7 \\
\hline & $\begin{array}{l}\text { Insufficient consumption of } \\
\text { fruits and vegetables }\end{array}$ & & & & & & 1.12 & 1.01 & 1.25 & 39.7 & 4.5 \\
\hline \multirow{2}{*}{$\begin{array}{l}\text { Post-menopausal } \\
\text { breast cancer }\end{array}$} & Obesity & & & & & & 1.15 & 1.08 & 1.23 & 15.4 & 4.3 \\
\hline & Overweight & & & & & & 1.08 & 1.03 & 1.23 & 27.1 & \\
\hline \multirow{3}{*}{$\begin{array}{l}\text { Colon and rectum } \\
\text { cancer }\end{array}$} & Obesity & 1.95 & 1.59 & 2.39 & 17.5 & 27.3 & 1.66 & 1.52 & 1.81 & 15.4 & 18.3 \\
\hline & Overweight & 1.51 & 1.37 & 1.67 & 41.0 & & 1.45 & 1.30 & 1.62 & 27.1 & \\
\hline & Physical inactivity & 1.26 & 1.10 & 1.47 & 58.2 & 13.1 & 1.40 & 1.13 & 1.74 & 63.5 & 20.3 \\
\hline \multicolumn{12}{|l|}{$\begin{array}{l}\text { (3) Cardiovascular } \\
\text { diseases }\end{array}$} \\
\hline \multirow[t]{6}{*}{ Stroke } & Obesity & 1.26 & 1.07 & 1.48 & 17.5 & 6.2 & 1.26 & 1.07 & 1.48 & 15.4 & 5.1 \\
\hline & Overweight & 1.05 & 0.93 & 1.17 & 41.0 & & 1.05 & 0.93 & 1.17 & 27.1 & \\
\hline & $\begin{array}{l}\text { Insufficient consumption of } \\
\text { fruits and vegetables }\end{array}$ & 1.20 & 1.12 & 1.30 & 56.7 & 10.4 & 1.05 & 0.96 & 1.14 & 39.7 & 2.0 \\
\hline & Physical inactivity & 1.25 & 1.15 & 1.35 & 58.2 & 12.7 & 1.22 & 1.14 & 1.32 & 63.5 & 12.3 \\
\hline & Smoker & 1.43 & 1.35 & 1.52 & 25.2 & 15.3 & 1.72 & 1.59 & 1.86 & 20.6 & 17.6 \\
\hline & Former smoker & 1.17 & 1.05 & 1.88 & 42.3 & & 1.17 & 1.05 & 1.88 & 38.8 & \\
\hline \multirow{6}{*}{$\begin{array}{l}\text { Ischemic heart } \\
\text { diseases }\end{array}$} & Obesity & 1.72 & 1.51 & 2.24 & 17.5 & 19.7 & 3.10 & 2.81 & 3.43 & 15.4 & 35.1 \\
\hline & Overweight & 1.29 & 1.18 & 1.41 & 41.0 & & 1.80 & 1.64 & 1.98 & 27.1 & \\
\hline & $\begin{array}{l}\text { Insufficient consumption of } \\
\text { fruits and vegetables }\end{array}$ & 1.11 & 1.02 & 1.22 & 56.7 & 5.9 & 1.32 & 0.95 & 1.82 & 39.7 & 11.1 \\
\hline & Physical inactivity & 1.10 & 0.96 & 1.30 & 58.2 & 5.5 & 1.25 & 1.09 & 1.45 & 63.5 & 13.7 \\
\hline & Smoker & 1.60 & 1.26 & 2.02 & 25.2 & 12.8 & 3.22 & 2.47 & 4.22 & 20.6 & 34.0 \\
\hline & Former smoker & 0.99 & 0.69 & 1.42 & 42.3 & & 1.15 & 0.92 & 1.44 & 38.8 & \\
\hline \multirow[t]{5}{*}{ Hypertension } & Obesity & 1.84 & 1.51 & 2.24 & 17.5 & 20.7 & 2.42 & 1.59 & 3.67 & 15.4 & 28.3 \\
\hline & Overweight & 1.28 & 1.10 & 1.50 & 41.0 & & 1.65 & 1.24 & 2.19 & 27.1 & \\
\hline & Physical inactivity & 1.47 & 1.11 & 2.70 & 58.2 & 21.5 & 1.47 & 1.11 & 2.70 & 63.5 & 23.0 \\
\hline & Smoker & 1.15 & 1.03 & 1.27 & 25.2 & 6.7 & 1.15 & 1.03 & 1.27 & 20.6 & 5.8 \\
\hline & Former smoker & 1.08 & 1.01 & 1.15 & 42.3 & & 1.08 & 1.01 & 1.15 & 38.8 & \\
\hline \multicolumn{12}{|l|}{ (4) Metabolic diseases } \\
\hline \multirow[t]{4}{*}{ Type II diabetes } & Obesity & 6.48 & 5.17 & 8.13 & 17.5 & 61.9 & 8.38 & 5.46 & 12.85 & 15.4 & 65.1 \\
\hline & Overweight & 2.63 & 2.09 & 3.32 & 41.0 & & 3.69 & 2.52 & 5.40 & 27.1 & \\
\hline & $\begin{array}{l}\text { Insufficient consumption of } \\
\text { fruits and vegetables }\end{array}$ & 1.20 & 1.11 & 1.32 & 58.2 & 10.4 & 1.20 & 1.11 & 1.32 & 63.5 & 11.3 \\
\hline & Physical inactivity & 1.04 & 0.85 & 1.27 & 56.7 & 2.2 & 1.04 & 0.85 & 1.27 & 39.7 & 1.6 \\
\hline
\end{tabular}


Table 2 continued

\begin{tabular}{|c|c|c|c|c|c|c|c|c|c|c|c|}
\hline \multirow[t]{2}{*}{ Chronic diseases } & \multirow[t]{2}{*}{ Risk factors (RF) } & \multicolumn{5}{|l|}{ Men } & \multicolumn{5}{|c|}{ Women } \\
\hline & & $\mathrm{RR}^{\mathrm{a}}$ & $(95 \%$ & $\left.\mathrm{CI}^{\mathrm{b}}\right)$ & $P^{\mathrm{c}}(\%)$ & $\begin{array}{l}\text { Adj. } \\
\text { PAF }^{\mathrm{d}}(\%)\end{array}$ & $\mathrm{RR}^{\mathrm{a}}$ & $(95 \%$ & $\left.\mathrm{I}^{\mathrm{b}}\right)$ & $P^{\mathrm{c}}(\%)$ & $\begin{array}{l}\text { Adj. } \\
\text { PAF }^{d}(\%)\end{array}$ \\
\hline \multicolumn{12}{|c|}{$\begin{array}{l}\text { (5) Musculoskeletal } \\
\text { diseases }\end{array}$} \\
\hline \multirow[t]{2}{*}{ Osteoarthritis } & Obesity & 4.20 & 2.76 & 6.41 & 17.5 & 56.2 & 1.96 & 1.88 & 2.04 & 15.4 & 26.7 \\
\hline & Overweight & 2.76 & 2.05 & 3.70 & 41.0 & & 1.80 & 1.75 & 1.85 & 27.1 & \\
\hline \multicolumn{12}{|l|}{ Canada 2016} \\
\hline \multicolumn{12}{|l|}{${ }^{a}$ Relative risk } \\
\hline \multicolumn{12}{|c|}{ b Confidence interval } \\
\hline \multicolumn{12}{|l|}{${ }^{c}$ Prevalence } \\
\hline${ }^{\mathrm{d}}$ Population att & e fraction & & & & & & & & & & \\
\hline
\end{tabular}

at $\$ 1.958$ billion in 2010. As such, the cost of the HLHP strategy (\$110 million) represents only $5.6 \%$ of the healthcare expenditures associated with these risk factors. In another study conducted in Manitoba, Krueger et al. (2013) estimated the direct costs attributable to the same risk factors as considered in our study to be $\$ 490$ million in 2008, substantially lower than our estimate. However, when adjusted for the number of inhabitants per province, the costs associated with these risk factors in the Manitoba study (\$409 per capita; total population of $1,197,774$ in Manitoba in 2008) are higher than our estimates (\$247 per capita; total population of 7,923,365 in Quebec) (Statistics Canada 2014). This difference may be explained by a different study design and different risk factors retained for the assessment of total healthcare expenditures. In the study by Krueger et al. (2013), the indirect costs of these risk factors, notably the costs of lost productivity, longterm disability, and mortality — which were not included in our study-represented $70 \%$ of total costs $(\$ 1.114$ billion out of a total $\$ 1.6$ billion). This highlights the magnitude of the indirect costs associated with these risk factors in Canada. In our study, if the indirect costs associated with these risk factors represented $70 \%$ of the total costs, the total costs would be $\$ 6.53$ billion.

\section{Challenges}

Several challenges emerged during this evaluation (Drummond et al. 2008; Shiell et al. 2008; Weatherly et al. 2009). First, a health promotion strategy is not a single, confined intervention; it is in fact a number of actions, interventions, and programs with a common orientation, each with its own costs and funding, and leading to widespread and long-term effects with complex causalities (Craig et al. 2008). Developing a complete and accurate description of all activities related to the HLHP strategy as well as their sources of funding represented a challenge in itself. Nevertheless, the fact that the HLHP strategy included all activities related to healthy habits, allowed us to work with attributable risks for estimating the potential healthcare cost savings at the provincial level.

Second, the element of time is likely to influence these results (Soler et al. 2016), although it is difficult to foresee in what way. First, illness-related costs will be avoided over a certain number of years, but it is impossible to estimate this time horizon with any precision. We performed sensitivity analyses assuming avoided expenditures at time horizons of 5, 10, 15, and 20 years by discounting, with various discount rates, attributable costs and adjusting for expenditure increases over time. The results of these analyses indicated that taking into account the time horizon has a limited impact, as the discount rates are similar to the annual rates of increases in health expenditures in Canada (4.4\%). Such analyses also run into certain methodological limitations, such as the difficulty of forecasting time horizons for effects and of anticipating changes in disease management approaches. These methodological limitations may influence, in either direction, the costs of treatment and future savings generated by the HLHP strategy. Moreover, identifying activity costs is a challenge when dealing with a strategy encompassing many activities. Some costs may not have been listed and others may have been overestimated or underestimated. To counteract this limitation, we used high estimates of activity costs in modelling to be sure of obtaining conservative results. We also performed sensitivity analyses to assess the impacts of program and activity cost variations on our results.

\section{Strengths}

To estimate the portion attributable to each risk factor, we used measures of association drawn from a literature review (See Table S1 in Supplemental material), with strict 
Table 3 Direct healthcare costs associated to lifestyle-related risk factors

\begin{tabular}{|c|c|c|c|c|c|}
\hline Chronic diseases & $\begin{array}{l}\text { Direct healthcare } \\
\text { costs (CAN \$2010) }\end{array}$ & Risk factors (RF) & $\begin{array}{l}\text { Adj. } \text { PAF }^{\mathrm{a}} \\
(\%)\end{array}$ & $\begin{array}{l}\text { Costs attributable to } \\
\text { risk factors }(\$)\end{array}$ & $\begin{array}{l}\text { Total costs adjusted } \\
\text { for multiple } \\
\text { exposition }(\$)\end{array}$ \\
\hline \multicolumn{6}{|l|}{ (1) Pulmonary diseases } \\
\hline \multirow{2}{*}{$\begin{array}{l}\text { Chronic Obstructive } \\
\text { Pulmonary disease }\end{array}$} & \multirow[t]{2}{*}{$\$ 394,736,365$} & Smoking & 49.52 & $\$ 195,464,225$ & \multirow[t]{2}{*}{$\$ 221,658,019$} \\
\hline & & $\begin{array}{l}\text { Insufficient consumption of } \\
\text { fruits and vegetables }\end{array}$ & 13.14 & $\$ 51,887,048$ & \\
\hline \multirow[t]{2}{*}{ Asthma } & \multirow[t]{2}{*}{$\$ 335,893,285$} & Smoking & 9.88 & $\$ 33,195,061$ & \multirow[t]{2}{*}{$\$ 77,751,443$} \\
\hline & & Obesity and overweight & 14.72 & $\$ 49,442,607$ & \\
\hline \multicolumn{6}{|l|}{ (2) Cancers } \\
\hline \multirow[t]{2}{*}{ Lung cancers } & \multirow[t]{2}{*}{$\$ 151,601,720$} & Smoking & 70.56 & $\$ 106,973,175$ & \multirow[t]{2}{*}{$\$ 111,056,160$} \\
\hline & & $\begin{array}{l}\text { Insufficient consumption of } \\
\text { fruits and vegetables }\end{array}$ & 9.15 & $\$ 13,869,767$ & \\
\hline \multirow[t]{2}{*}{ Breast cancers } & \multirow[t]{2}{*}{$\$ 77,422,929$} & Physical inactivity & 4.55 & $\$ 3,520,702$ & \multirow[t]{2}{*}{$\$ 21,058,496$} \\
\hline & & $\begin{array}{l}\text { Insufficient consumption of } \\
\text { fruits and vegetables }\end{array}$ & 23.73 & $\$ 18,373,294$ & \\
\hline $\begin{array}{l}\text { Post-menopausal } \\
\text { breast cancers }\end{array}$ & $\$ 61,164,114$ & Obesity and overweight & 4.29 & $\$ 2,621,537$ & $\$ 2,621,537$ \\
\hline \multirow{2}{*}{$\begin{array}{l}\text { Colon and rectum } \\
\text { cancers }\end{array}$} & \multirow[t]{2}{*}{$\$ 131,935,455$} & Obesity and overweight & 22.71 & $\$ 29,963,004$ & \multirow[t]{2}{*}{$\$ 47,049,393$} \\
\hline & & Physical inactivity & 16.76 & $\$ 22,106,957$ & \\
\hline \multicolumn{6}{|l|}{$\begin{array}{l}\text { (3) Cardiovascular } \\
\text { diseases }\end{array}$} \\
\hline \multirow[t]{4}{*}{ Stroke } & \multirow[t]{4}{*}{$\$ 457,390,301$} & Smoking & 16.48 & $\$ 75,356,930$ & \multirow[t]{4}{*}{$\$ 161,321,080$} \\
\hline & & $\begin{array}{l}\text { Insufficient consumption of } \\
\text { fruits and vegetables }\end{array}$ & 6.17 & $\$ 28,230,351$ & \\
\hline & & Physical inactivity & 12.48 & $\$ 57,064,937$ & \\
\hline & & Obesity and overweight & 5.63 & $\$ 25,751,457$ & \\
\hline \multirow[t]{4}{*}{ Ischemic heart diseases } & \multirow[t]{4}{*}{$\$ 963,691,242$} & Smoking & 23.55 & $\$ 226,961,558$ & \multirow[t]{4}{*}{$\$ 522,497,040$} \\
\hline & & $\begin{array}{l}\text { Insufficient consumption of } \\
\text { fruits and vegetables }\end{array}$ & 8.57 & $\$ 82,558,945$ & \\
\hline & & Physical inactivity & 9.67 & $\$ 93,144,537$ & \\
\hline & & Obesity and overweight & 27.50 & $\$ 264,972,860$ & \\
\hline \multirow[t]{3}{*}{ Hypertension } & \multirow[t]{3}{*}{$\$ 968,824,255$} & Smoking & 6.25 & $\$ 60,584,638$ & \multirow[t]{3}{*}{$\$ 436,253,706$} \\
\hline & & $\begin{array}{l}\text { Insufficient consumption of } \\
\text { fruits and vegetables }\end{array}$ & 22.24 & $\$ 215,504,459$ & \\
\hline & & Obesity and overweight & 24.59 & $\$ 238,211,364$ & \\
\hline \multicolumn{6}{|l|}{ (4) Metabolic disease } \\
\hline \multirow[t]{3}{*}{ Type II diabetes } & \multirow[t]{3}{*}{$\$ 379,683,944$} & $\begin{array}{l}\text { Insufficient consumption of } \\
\text { fruits and vegetables }\end{array}$ & 1.89 & $\$ 7,161,712$ & $\$ 258,622,744$ \\
\hline & & Physical inactivity & 10.85 & $\$ 41,212,151$ & \\
\hline & & Obesity and overweight & 63.55 & $\$ 241,271,621$ & \\
\hline (5) Musculoskeletal disea & & & & & \\
\hline Osteoarthritis & $\$ 238,593,747$ & Obesity and overweight & 41.21 & $\$ 98,326,933$ & $\$ 98,326,933$ \\
\hline $\begin{array}{l}\text { Direct costs of chronic } \\
\text { diseases }\end{array}$ & $\$ 4,160,937,358$ & & & $\begin{array}{l}\text { Total costs } \\
\text { attributable to risk } \\
\text { factors }\end{array}$ & $\$ 1,958,216,550$ \\
\hline
\end{tabular}

Canada 2016

a Population attributable fraction

selection criteria that would most closely approximate the characteristics of the population of Quebec. This approach meant that the selected measures of association could not be directly attributed to the study population. Nevertheless, to limit this bias and to estimate the proportions that could be attributable, we developed an approach that allowed for 
systematic selection of measures of association and incorporated a sensitivity analysis. This approach can be replicated in other contexts and makes it possible, using criteria from the studies identified in the literature review, to prioritize RRs in ways that will ensure the study population is represented as accurately as possible.

The originality of our study is that it compares investments in health promotion activities against amounts devoted to treating major diseases associated with the targeted risk factors. We have no effectiveness data, but we believe that achieving the healthy lifestyle objectives set by the MSSS would result in considerable savings that would completely finance the HLHP strategy. Although it is difficult to change people's lifestyle habits, efforts over recent years to reduce smoking in Quebec have lowered smoking prevalence from $27 \%$ in 2003 to $24 \%$ in 2009-10 (DGSP 2012). In comparison with the burden that lifestyle habits related diseases will represent in coming years according to current epidemiological trends, investments in HLHP activities seem relatively small (Poirier and Jobin 2011). Our results indicate as it is likely that even a small effectiveness in risk reduction could produce important savings for the healthcare system in terms of costs averted.

\section{Conclusion}

Lifestyle-related illnesses have become a major public health concern around the world over recent years, and the growing prevalence all around the world is a serious concern for public health authorities (Geneau et al. 2010). In this article, we show that it is possible to conduct an economic evaluation of a large-scale health promotion strategy encompassing multiple interventions, activities, and programs. The methodology we used is situated at the intersection of several fields. We combined methods from the fields of evaluation, economic evaluation, and epidemiology. We were able to assess the economic value of the HPHL strategy by comparing its costs to the healthcare expenditures associated with diseases related to targeted risk factors.

Our study demonstrates that the financial risk of investing in health promotion activities aimed at improving lifestyle habits is small when compared with the financial burden of diseases associated with the targeted risk factors.

Acknowledgments The authors are grateful to the Directorate of Public Health of Quebec's Ministry of Health and Social Services for its financial support of this research project. We would also like to thank the Fonds de Recherche du Québec-Santé (FRQS) and the Canadian Institutes of Health Research (CIHR), which funded Astrid Brousselle's Canada Research Chair in Evaluation and Health System Improvement, and the CIHR's 4P Training Program (promotion, prevention and public policy) and Population Health Intervention Research Network program (PHIRNET), which funded Eric Tchouaket's postdoctoral award. CIHR also funded
Pierre-Alexandre Dionne's doctoral award and Alvine Fansi's postdoctoral fellowship. The authors declare that they have no conflict of interest. We would like to thank the Canadian Institutes of Health Research (CIHR) and the Fonds de recherche du Québec - Santé (FRQS) which fund the Canada Research Chair in Evaluation and Health System Improvement held by Astrid Brousselle and also funded the postdoctoral fellowships of Éric Tchouaket (4P Training Program: Prevention, Promotion and Public Policy, and PHIRNET: Population Health Intervention Research Network) and Alvine Fansi. We also extend our thanks to the following experts for their generous collaboration and contributions: Ginette Lafontaine, Annie-Claude Voisine, Lyne Mongeau, Douglas Manuel, Emilie Dionne.

Open Access This article is distributed under the terms of the Creative Commons Attribution 4.0 International License (http:// creativecommons.org/licenses/by/4.0/), which permits unrestricted use, distribution, and reproduction in any medium, provided you give appropriate credit to the original author(s) and the source, provide a link to the Creative Commons license, and indicate if changes were made.

\section{References}

Abraham C, Kelly MP, West R, Michie S (2009) The UK National Institute for Health and Clinical Excellence public health guidance on behaviour change: a brief introduction. Psychol Health Med 14:1-8

Benichou J (2001) A review of adjusted estimators of attributable risk. Stat Methods Med Res 10:195-216

Brousselle A, Champagne F (2011) Program theory evaluation: logic analysis. Eval Progr Plan 34:69-78

Brownson RC, Haire-Joshu D, Luke DA (2006) Shaping the context of health: a review of environmental and policy approaches in the prevention of chronic diseases. Ann Rev Public Health 27:341-370

Canadian Agency for Drugs and Technologies in Health (CADTH) (2006) Guidelines for the economic evaluation of health technologies: Canada, 3rd edn. Canadian Agency for Drugs and Technologies in Health, Ottawa

Canadian Institute for Health Information (CIHI) (2012) National Health Expenditure Trends, 1975 to 2011. Ottawa: Canadian Institute for Health Information. https://secure.cihi.ca/free_ products/nhex_trends_report_2011_en.pdf. Accessed 16 June 2014

Chiles JA, Lambert MJ, Hatch AL (1999) The impact of psychological interventions on medical cost offset: a meta-analytic review. Clin Psychol Sci Pract 6:204-220

Coast J (2004) Is economic evaluation in touch with society health values? BMJ 329:1233-1236

Cohen JT, Neumann PJ, Weinstein MC (2008) Does preventive care save money? Health economics and the presidential candidates. N Engl J Med 358:661-663

Commonwealth Department of Health and Ageing (2003) Returns on investment in public health. An epidemiological and economic analysis prepared for the Department of Health and Ageing. Canberra: Commonwealth Department of Health an Ageing. http://archive.oxha.org/knowledge/publications/australgvt_ returns_on_investment_2003.pdf. Accessed 16 June 2014

Conference Board of Canada (2010) The Canadian heart health strategy: risk factors and future cost implications. The Conference Board of Canada, Ottawa 
Craig P, Dieppe P, Macintyre S, Michie S, Nazareth I, Petticrew M (2008) Developing and evaluating complex interventions: the new Medical Research Council guidance. BMJ 337:1655

Direction générale de la santé publique (DGSP) (2010) Coûts normés du Programme national de santé publique 2003-2012-Mise à jour 2008. Version finale pour l'allocation des ressources 2010-2011 [Standard costs for the National Public Health Program 2003-2012, updated, 2010-2011 ressource allocation]. Québec. Ministère de la Santé et des Services Sociaux

Direction générale de la santé publique (DGSP) (2012) Suivi des indicateurs sociosanitaires [Follow-up on social and health indicators]. Direction générale adjointe de la santé publique, Ministère de la Santé et des Services sociaux. June 2012

Drummond MF, Sculpher MJ, Torrance GW, O'Brien BJ, Stoddart GL (2005) Methods for the economic evaluation of health care programs, 3rd edn. Oxford University Press, New York

Drummond M, Weatherly H, Ferguson B (2008) Economic evaluation of health interventions. BMJ 337:a1204

Funnell SC, Rogers PJ (2011) Purposeful program theory: Effective use of theories of change and logic models. Jossey-Bass/Wiley, San Francisco

Geneau R, Stuckler D, Stachenko S, McKee M, Ebrahim S, Basu S, Chockalingham A, Mwatsama M, Jamal R, Alwan A, Beaglehole R (2010) Raising the priority of preventing chronic diseases: a political process. Lancet 376:1689-1698

Goldsmith L, Hutchison B, Hurley J (2004) Economic evaluation across the four faces of prevention: a Canadian perspective. McMaster University, Centre for Health Economics and Policy Analysis. http://evaluationcanada.ca/distribution/200405_ goldsmith_laurie_hutchison_brian_hurley_jeremiah.pdf. Accessed 16 June 2014

Hanley JA (2001) A heuristic approach to the formulas for population attributable fraction. $\mathrm{J}$ Epidemiol Community Health 55:508-514

Health Canada (2002) The economic burden of illness in Canada, 1998. Ottawa: Health Canada. http://publications.gc.ca/ collections/Collection/H21-136-1998E.pdf. Accessed 16 June 2014

Katzmarzyk PT, Janssen I (2004) The economic costs associated with physical inactivity and obesity in Canada: an update. Can J Appl Physiol 29:90-115

Kelly MP, McDaid D, Ludbrook A, Powell J (2005) Economic appraisal of public health interventions [Briefing paper]. NHS Health Development Agency, London

Krueger H, Williams D, Ready AE, Trenaman L, Turner D (2013) Improved estimation of the health and economic burden of chronic disease risk factors in Manitoba. Chron Dis Inj Can 33:236-246

Manuel DG, Creatore MI, Rosella LC, Henry DA (2009) What does it take to make a healthy province? A benchmark study of jurisdictions in Canada and around the world with the highest levels of health and the best health behaviours. Institute for Clinical Evaluative Sciences, Toronto

Ministère de la Santé et des Services sociaux (MSSS) (2008) Programme national de santé publique 2003-2012, mise à jour 2008 [National Public Health Program 2003-2012, updated 2008]. Québec: Government of Québec. http://publications.msss. gouv.qc.ca/acrobat/f/documentation/2008/08-216-01.pdf. Accessed 16 June 2014

National Institute for Health and Clinical Excellence (NICE) (2011) Supporting investment in public health: Review of methods for assessing cost effectiveness, cost impact and return on investment. Proof of concept report. NICE, London

Neumann PJ, Jacobson PD, Palmer JA (2008) Measuring the value of public health systems: The disconnect between health economists and public health practitioners. Am J Public Health 98:2173-2180

Poirier A, Jobin L (2011) Pour guider l'action. Portrait de santé du Québec et de ses régions [To guide action. Health Situation for Quebec and region]. Gouvernement du Québec

Public Health Agency of Canada (PHAC) (2000) Data on the Economic Burden of Disease in 2000. On files. Data obtained from Serge Tanguay, Manager of data for health. Public Health Agency of Canada

Scarborough P, Bhatnagar P, Wickramasinghe KK, Allender S, Foster C, Rayner M (2011) The economic burden of ill health due to diet, physical inactivity, smoking, alcohol and obesity in the UK: update to 2006-07 NHS costs. J Public Health 33:527-535

Shiell A, Hawe P, Gold L (2008) Complex interventions or complex systems? Implications for health economic evaluation. BMJ 336:1281-1283

Soler R, Orenstein D, Honeycutt A, Bradley C, Trogdon J (2016) Community-Based Interventions to Decrease Obesity and Tobacco Exposure and Reduce Health Care Costs: Outcome Estimates From Communities Putting Prevention to Work for 2010-2020. Prev Chron Dis 13:150272

Statistics Canada (2014) Table 051-0001 Estimates of population, by age group and sex for July 1, Canada, provinces and territories, annual (persons unless otherwise noted), CANSIM (database). Accessed 16 June 2014

Steenland K, Armstrong B (2006) An overview of methods for calculating the burden of disease due to specific risk factors. Epidemiology 17:512-519

Tchouaket E, Brousselle A, Fansi A et al (2013) The economic value of Quebec's water fluoridation program. Z Gesundh Wiss 21:523-533

Weatherly H, Drummond M, Claxton K, Cookson R, Ferguson B, Godfrey C, Rice N, Sculpher M, Sowden A (2009) Methods for assessing the cost-effectiveness of public health interventions: key challenges and recommendations. Health Policy 93:85-92 